henge. Here, and throughout the authors make good use of clear diagrams and some simple geometry to explain details. In the early chapters they do, to my mind, make too much of the idea that most of the content of related archaic myths is induced by astronomical experiences since these were the only universal experiences of early peoples. If we look at the laws of ancient societies we also find an unexpected homogeneity, yet no one would claim that this was astronomically induced.

The ancients lead inevitably to the Greeks and they to the Medievals. Medieval Science was but Greek science written in Latin. Unfortunately, the nonEuropean cultures are all but excluded from the description; nor do the authors ever dwell on the interesting question as to why science developed so effectively in Europe whilst the early Eastern and Oriental successes faded. Some treatment of non-European scientific development would have been valuable, if only because there have recently been a number of ridiculous publications about the relationship of modern physics to Eastern religions.

The Medievals lead inevitably to chapters on Copernicus and Galileo. We see the end of the medieval mindset: the authority of texts gives way to the authority of observations. But, the new dogma, like the old, also has its problems if applied inflexibly, for Copernicus had no concept of the inevitable experimental error associated with any observation or measurement. The authors show how this blindspot influenced Copernicus' deductions and point out that even Newton and his contemporaries failed to appreciate the relation of theoretical predictions to actual measurements. The Copernican development is a good illustration of the 'Whig' approach, as it always appears as the turning point in the history of astronomy. In retrospect, of course, it is; what is now equally clear is that $D e$ Revolutionibus orbium celestium had negligible influence until the seventeenth century. Few copies of it were sold, and even fewer read in the early years after Copernicus' death. Other great events, like the Portuguese voyages of discovery, entirely overshadowed it.

The next stop is Newton and the Principia. After this there is a leap into modern times. General relativity, the big bang and gravitational collapse make up the last quarter of the book. Although the treatment of these subjects is accurate it is extremely lightweight. More mathematical detail was devoted to explaining Ptolemaic epicycles than special relativity. Also, the brief description of elementary particles and the role of symmetry principles was too brief to be of any value.

Another gap in the development was to ignore the way theories were evaluated and the relationship of cosmology to philosophy. In ancient times these two lines of thought regarding the 'frame of the universe' were inseparable but after Descartes no philosopher made a significant contribution to science. The modern era sees a divide between the two disciplines, each of which cultivate different interests. A discussion of how this divide arose and what now distinguishes the two approaches would have been valuable. Also, the authors ignore discussing another modern development: how science thinks about itself. Most scientists take as their article of faith some version of Popper's naive falsification as a guiding principle. However, others following Duhem have stressed that hypotheses can only be tested in bundles, never in isolation. We can save any cherished

\section{Celestial talk}

\section{A. Rupert Hall}

\section{Telescopes, Tides, and Tactics:} A Galilean Dialogue about the Starry Messenger and Systems of the World. By Stillman Drake.

University of Chicago Press: 1983.

Pp.236. \$22.50, £18.

THE translator of all the genuine Galilean dialogues, Stillman Drake, after presenting his version of Galileo's early work in physics in the form of an imaginary dialogue between three of Galileo's friends under the title Cause, Experiment and Science, now employs the same vehicle to describe the first few years of Galileo's activity as an astronomer.

The scene is Venice, the year 1613. Galileo is in Florence. The learned talk is between Sagredo and Salviati - two friends whom Galileo himself used as expositors - and Paolo Sarpi, a religious and a philosopher, another real friend of Galileo's introduced here because Galileo first outlined his theory of the tides to Sarpi (in 1595) and first stated to him the law of fall (in 1604). The talk, without 'Prithees' and 'Forsooths', is in the modern language of a translator, in a style (to my ear) rather more formal and stilted than that actually employed by Galileo himself. Perhaps as these are imitations of imaginary conversations, that is right. Whether the dialogue form is preferable to straightforward historical exposition is a matter of taste; the facts and arguments are clear enough here, and Drake provides references for those sentences that have been lifted more or less literally from Galileo's own writings.

A substantial part of the book is the 'reading' of Galileo's Starry Messenger (Sidereus Nuncius, 1610), of which Drake published a partial English version many years ago. The printing of a complete translation now, with all the details of Galileo's observations of Jupiter's satellites, enables Drake to give an analysis - part historical, part reconstruction - of Galileo's longest hypothesis from falsification indefinitely by invariably picking as false another member of the 'bundle' involved in the experiment. In fact, the way in which the false assumption is picked from the 'bundle' is largely what separates 'crank' science from real science.

This was a book I enjoyed reading and one which undergraduates in historical subjects should find useful as an introductory guide. British science students suffering from educational overspecialization might also enjoy seeing when and how authority changed.

John D. Barrow is a Lecturer in Astronomy at the University of Sussex.

continued, most exact and most frustrating investigation in observational astronomy, which never yielded that practical solution to the problem of longitude at sea, ardently hoped for by the discoverer. This analysis, in turn, adds further substance to Drake's view of Galileo as, above all, an empirical investigator of nature.

There are many other issues raised in the dialogue, not all of them firmly resolved (it is a real advantage of the conversational vehicle that it allows a degree of uncertainty common in life but rare in historians). It starts from the question: why

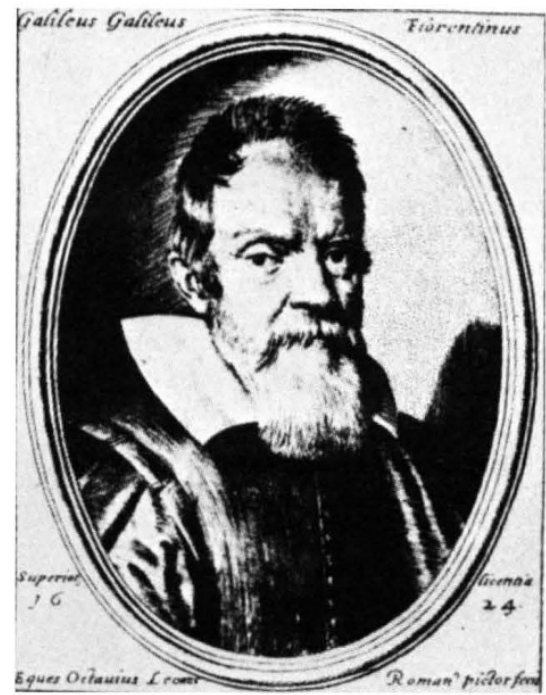

Galileo Galilei

has Galileo not published the System of the World announced in print in 1610 and in private even earlier? This, together with the related theme of the mechanical explanation of the tides, permits Drake to put forward new ideas about Galileo's development as an exponent of the new astronomy - in which context his relationship with Kepler, another theme, is also relevant. In particular Drake introduces the plausible hypothesis that Galileo whom history knows only as a student of motion for his first thirty years and more was led to take Copernicanism seriously by hitting upon his 'inertial' explanation of the tides (1595). This explanation was, 
Drake argues, central to Galileo's astronomical system, though it was pushed somewhat into the background by papal pressure before the publication of the Dialogo of 1632 .

Drake does not here defend the scientific adequacy of Galileo's theory of tides, nor the adequacy of his concept of inertia, nor one or two other positions which have seemed idiosyncratic to other scholars. His 'reconstructions' are balanced, clever, and well-documented. As in other books by him, 'the philosophers' come in for a good many hard knocks: 'There is a vast difference between confidence grounded in repeated observations and careful thought, and the confidence of philosophers in metaphysical principles that transcend all experience of mere astronomers', remarks Salviati. Drake (and other scholars) have successfully vindicated their claim for the historical veracity of Galileo's experimental approach to mechanics; here he extends the lesson to the successful matching of mathematical formulations with carefully compiled observations on Galileo's part. There is a great deal here which is new and really important. Drake stands with those who argue that the historical process of the separation of natural science from philosophy, metaphysics and, indeed, magic was just as important as the fact of the continuity of elements derived from these sources in natural science. For it was by separation that the special character of science was established.

Drake has tried to give a new and more lively form to the often pedantic literature of the history of science, and so to arouse a new curiosity. Whether or not he succeeds in that aim, his imaginary conversations, like those of Galileo himself, contain new truths vividly argued.

A. Rupert Hall is Emeritus Professor of the History of Science, Imperial College, University of London.

\section{Stepping through the Universe}

\section{A.T. Winfree}

Powers of Ten: About the Relative Size of Things in the Universe.

By Philip Morrison and Phylis Morrison and the Office of Charles and

Ray Eames.

W.H. Freeman: 1982. Pp.150.

$\$ 29.95$, £11.95.

TWELVE months ago, the editors of Scientific American launched the Scientific American Library as a book club, with books appearing at two month intervals, each being reissued as a trade book 12 months later at a higher price. Intended for a popular audience, the series is pitched at a level somewhere between the monthly magazine articles (which I personally consider demanding reading) and Time/Life picture books. Each is written by a scientist, many by Nobel Laureates, not by the editorial staff. Each presents a subject that cuts across diverse specialized disciplines. The first six issues have already been produced.

Powers of Ten is the premier issue and the first available to the general public. It is by far the least technical of the books produced up to now, and demonstrates the publishers' commitment to readability and quality graphics, in $22 \mathrm{~cm}$ square format with colour pictures on almost every page. The theme is familiar and not subtle: phenomena in the natural world vary over something like $\mathbf{4 2}$ orders of magnitude in linear dimensions (ignoring volume, time scales, etc.), and differ in character according to scale. Many books have presented this theme to diverse audiences. So in this case everything depends on targeting the right audience and on skill in presentation. The Morrisons' art work is superb, as one might have expected from their track record, and from the immediate antecedent of the book: the wonderfully succesful ten minute motion picture of 1968 and 1977 (improved) by the same name.

The core of Powers of Ten is a sequence of 42 colour plates, the first suggesting most of the Universe. In the next plate $\left(10^{24}\right.$ metres) some galactic clusters become big enough to see, as a giant step forward brings us ten times closer to the nucleus of a certain carbon atom in the very centre of that cosmic field of view . . . and so on through 42 steps. By the 25 th step we have converged on a couple lying on a picnic blanket and we continue, ending after 17 more steps in a subnuclear blur that might represent quarks.

Facing the colour plate at each step is a page of text and smaller pictures illustrating some of the phenomena characteristic of that size scale. For example facing the 10 metre to $10^{-6}$ metre pictures, most of the illustrations are biological. On every scale, the chosen examples are rich with surprising titbits of insight, presented from a unique perspective.

This core is only $60 \%$ of the book. The appendices are no less fascinating; in fact the one entitled "Rules for a Journey of Mind and Eye" might be the best place to start: it tells how the pictures were planned. My own taste is then to run backwards through the plates, starting with quarkblur. Other appendices gather some pertinent history of science; the 20 pages of "Sources and Notes" make particularly good reading.

A.T. Winfree is Professor of Biology at Purdue University, Indiana.
The Diversity of Green Plants

Third Edition

Peter Bell and Christopher Woodcock Contemporary Biology Series

A well-illustrated evolutionary account of the photosynthetic plants, from the algae to the flowering plants, paying particular attention to those plants prominent in current research. £9.95 paper 368 pages

\section{The Biology of Lichens}

\section{Third Edition}

Mason E. Hale

Contemporary Biology Series

A review of all aspects of lichenology.

This new edition has been rewritten, stressing ultrastructure studies and taking account of the tremendous progress in the study of lichen resynthesis and the physiology of symbiosis.

£8.95 paper 200 pages

\section{The Physiology of Flowering Plants}

Third Edition

H.E. Street and Helgi Opik

Contemporary Biology Series

This book treats plant physiology from the viewpoint of the whole plant or organ, with particular emphasis on growth and development. New additions to this edition include a treatment of the general physiology of photosynthesis, and an expansion of the topic of stress resistance.

£8.50 approx paper 296 pages fanuary

\section{Immunity to Parasites}

How animals control parasite infections

\section{Derek Wakelin}

The book concentrates on selected hostparasite systems, all of clinical or economic significance, which illustrate particular aspects of parasite adaptation and of host response, and in which immunologically oriented research has made significant progress.

£9.50 approx paper 192 pages March

\section{The Biology of the Coccidia}

Edited by Peter L. Long

This is the thoroughly revised and updated version of The Coccidia edited by the late Dr Hammond and Dr Long. It includes new chapters on chemotherapy and new details of life cycles of several species of Sarcocystis and Toxoplasma.

... this has turned out to be a significant volume which in the present climate of scientific work may have been produced just in time.' British Veterinary fournal $£ 45$ boards 512 pages

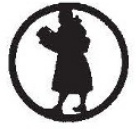

Edward Arnold

41 Bedford Square London WC1B 3DQ 